\title{
Sialendoscopy - a diagnostic and therapeutic approach subjectively rated by patients
}

\author{
Tomasz Kopeć ${ }^{1}$, Małgorzata Wierzbicka ${ }^{1}, K$ arolina Piskadło ${ }^{2}$, Mateusz Bednarek ${ }^{2}$, Witold Szyfter ${ }^{1}$ \\ ${ }^{1}$ ENT Department, Poznan University of Medical Sciences, Poznan, Poland \\ ${ }^{2}$ Poznan University of Medical Sciences, Poznan, Poland
}

Videosurgery Miniinv 2014; 9 (4): 505-510

DOI: $10.5114 /$ wiitm.2014.44176

\begin{abstract}
Introduction: Sialendoscopy is a miniinvasive procedure which shows the excretory ducts of the salivary glands. Aim: To evaluate patient satisfaction with sialendoscopy in submandibular and parotid gland sialolithiasis.

Material and methods: The study group included 100 consecutive patients with sialolithiasis, treated by means of sialendoscopy. The analysis was designed prospectively. The patients answered closed questions of our own, in-house made questionnaire.

Results: The number of sialendoscopic procedures necessary for symptom resolution ranged from 1 to 3 . The mean value was 1.2 and the median was 1. In 64 patients (64\%) one procedure was sufficient for symptom resolution, while 10 (10\%) and 8 (8\%) patients required 2 and even 3 procedures, respectively. Sixty-three patients (63\%) did not report any postoperative complications; 33 patients (33\%) reported transient swelling of the submandibular region and 4 patients (4\%) reported inflammation of the salivary gland. The level of treatment efficacy was $82 \%$. Among 53 patients treated using sialendoscopy for the first time $92.3 \%$ rated this approach subjectively as a very good or good technique, whereas among 47 patients who had previously undergone non-endoscopic treatment, this percentage increased to $96.4 \%$. The general level of satisfaction with the applied method did not depend on the age, gender, duration of ailments, the number of previously performed procedures or the number of sialendoscopic procedures necessary to obtain improvement and postoperative complications.

Conclusions: Sialendoscopy may be performed practically in any case without risking the patient's discomfort or unpleasant experience. Assessment of sialendoscopy by the patients confirmed the minimally invasive character of this technique.
\end{abstract}

Key words: quality of life, sialendoscopy, sialolithiasis.

\section{Introduction}

Assessment of the quality of life and the degree of patient satisfaction are parameters that are important and increasingly often considered in treatment planning and selection of diagnostic and therapeutic approaches. Sialendoscopy was first introduced in the treatment of sialolithiasis in 1991 by Katz [1, 2]. It is a technique still gaining approval worldwide.
The application of endoscopy in salivary gland diseases has enabled combination of the diagnostic and therapeutic processes, with the micro-invasive nature of the procedure considerably unburdening the patients [3-6].

Patients usually rate their quality of life and level of satisfaction with the treatment using questionnaires. With a long-lasting tradition of collecting su-

\section{Address for correspondence}

Tomasz Kopeć MD, PhD, ENT Department, Poznan University of Medical Sciences, 49 Przybyszewskiego St, 60-355 Poznan, Poland,

phone: +48 6186913 87, e-mail: tkopec@ump.edu.pl 
bjective assessments and a thorough knowledge of the issue, in such branches of medicine as oncology, phoniatrics and rhinology, uniform, standardised European or global questionnaires have been developed. Such uniform diagnostic tools as EORTC used in oncology or $\mathrm{VHI}$ and GRBAS used in phoniatrics allow one to conduct multicenter comparisons of treatment results between groups of patients and various treatment techniques.

Studies on the usefulness of such a new approach as sialendoscopy cannot be based on any pattern. Thus, this prospective study uses a tailored scale, designed for patients who had undergone sal-

Table I. Questionnaire for patients who underwent sialendoscopy

Forename and surname:

Age:

Gender:

1. How long did you experience symptoms before the procedure?

$\square$ Up to 1 month

$\square 1-6$ months

$\square 6$ months -1 year

$\square 1-2$ years

$\square 2-5$ years

$\square$ More than 5 years

2. What symptoms did you experience?

$\square$ Pain

$\square$ Swelling of the submandibular region

$\square$ Swelling of the parotid region

$\square$ Other (please describe)

3. Date of the procedure:

4. Number of performed sialoendoscopic procedures:

5. Complications after sialendoscopy:

$\square$ None

$\square$ Oedema

$\square$ Inflammation of the gland

$\square$ Other (please describe)

6. Relief of symptoms:

$\square$ Yes

$\square$ No

$\square$ Partial improvement

$\square$ No improvement

$\square$ Deterioration

7. How do you rate the applied treatment approach:

$\square$ Very good

$\square$ Good

$\square$ Satisfactory

$\square$ Bad ivary gland treatment using the innovative approach presented above.

\section{Aim}

The aim of this study was to evaluate sialendoscopy in the treatment of salivary gland sialolithiasis as subjectively rated by the patients. The evaluation of the level of patient satisfaction was correlated with postoperative complications, efficacy of the procedure measured by symptom resolution, the number of sialendoscopic procedures necessary to cure the patient and the anamnesis involving previous treatment using non-endoscopic techniques.

\section{Material and methods}

The study was planned and conducted prospectively using a questionnaire. The study group included 100 consecutive patients with submandibular and parotid gland sialolithiasis treated by means of sialendoscopy at the Department of Otolaryngology and Laryngological Oncology of the Poznan University of Medical Sciences in the years 2009-2012. Sialolithiasis was confirmed in all patients using ultrasonography, with 11 patients additionally referred for a computed tomography (CT) scan and 5 spontaneously subjected to magnetic resonance imaging (MRI). The inclusion criterion was a history of recurrent swelling of the submandibular and parotid gland due to sialolithiasis. The exclusion criterion was obliteration of the salivary orifice. Our research was approved by the Bioethical Commission and all participants signed an informed consent form.

During interventional sialoendoscopy, $1.3 \mathrm{~mm}$ and $1.6 \mathrm{~mm}$ diameter endoscopes (Karl Storz Tutlingen, Germany, compact modular semirigid interventional endoscope with three channels) were used. Stones were removed with the help of the $0.4 \mathrm{~mm}$ diameter wire basket and forceps, introduced through the working canal. The sialoendoscopy procedure was carried out after premedication (midazolam, $7.5 \mathrm{mg}$ ) in local anaesthesia. One postoperative visit was performed 7 days after endoscopy. Four weeks after surgery the questionnaire was sent to the patient. To date, a validated questionnaire on patient satisfaction after sialendoscopy has not been designed. Our own, in-house made questionnaire on patient satisfaction was developed. The patients answered closed questions of the tailored questionnaire (Table I). The questions concerned the 
duration of ailments at baseline, nature of the symptoms, diagnosis and medical history. The second group of questions pertained to issues connected with sialendoscopic treatment. These included postoperative complications, treatment efficacy, i.e. relief of ailments, and general subjective assessment of satisfaction with the applied method. A review of validity, reliability and objectivity of the questionnaire was not possible.

Respondents involved the patients who underwent sialendoscopy in the years 2009-2012. The studied sample included 67 females and 33 males. Patients were aged between 17 and 82 years. The mean and median values were 52 and 54 years, respectively. The follow-up period was 12 to 24 months (14 months on average).

\section{Statistical analysis}

For statistic analysis Spearman's rank, KruskalWallis and Mann-Whitney U-tests were used.

\section{Results}

The first group of questions comprised retrospective data, obtained based on the anamnesis, involving the disease course prior to sialendoscopy. The ailments resulted from the pathological changes within the salivary glands. In 11 patients the duration of symptoms was below 6 months, in 45 patients it ranged from 6 months to 1 year, while in 20 and 24 patients it was $1-5$ years and over 5 years, respectively. In the group under study, pain was the dominant symptom and was reported by 62 patients (62\%). The second most often reported complaint was swelling, which was located in the submandibular region in 24 patients (24\%), in the parotid region in 13 patients (29\%), and in both submandibular and parotid regions in 18 patients (18\%) (Table II). A strong correlation between subjective syndromes (pain and swelling) and objective findings was found. The history of treatment prior to recruitment for sialendoscopy showed that incision of the salivary duct due to sialolithiasis had been conducted in 47 patients (47\%).

\section{Results of endoscopic treatment}

The number of sialendoscopic procedures necessary to relieve ailments ranged from 1 to 3 , with the mean and median values being 1.2 and 1 , respectively. The analysis comparing the number of
Table II. Preoperative symptoms

\begin{tabular}{|lcc|}
\hline Symptoms & Gland & $\begin{array}{c}\text { Number } \\
\text { of patients }\end{array}$ \\
\hline Pain & SMG & 37 \\
\cline { 2 - 3 } & PG & 25 \\
\hline Swelling & SMG & 24 \\
\cline { 2 - 3 } & Both & 13 \\
\hline Transient fever & SMG & 5 \\
\cline { 2 - 3 } & PG & 4 \\
\hline Saliva blockage & SMG & 12 \\
\cline { 2 - 3 } & PG & 5 \\
\hline Dryness and difficulty & SMG & 11 \\
\hline in swallowing & PG & 9 \\
\hline
\end{tabular}

SMG - submandibular gland, $P G$ - parotid gland

sialendoscopic procedures necessary to relieve the symptoms and the patients' age indicated no correlation. Likewise, no correlation was found between the patients' gender, the duration of ailments and the number of previously performed procedures of salivary duct incision.

The key issue of interest was subjective assessment of the applied sialendoscopic procedure in three aspects, namely post-treatment complications, symptom relief and patient general satisfaction with the approach. Data analysis based on the questionnaire is presented in Tables III and IV.

Complications were defined as a negative reaction observed after endoscopy. Sixty-three patients $(63 \%)$ reported no complications after the procedure, 33 patients (33\%) reported transient swelling of the submandibular or parotid region of low intensity, while 4 patients (4\%) complained of inflammation of the salivary gland. Eleven (11\%) respondents reported other complications, including elevated body temperature and minor pain. The mean and median values representing age in the group of patients who did not report any complications were 57.3 and 56 years, respectively, while in the group of patients who reported complications these values were 49.3 and 46 years, respectively. The difference was nearly statistically significant (Mann-Whitney $U$-test: $p=$ 0.053). Despite almost twice as frequent complications among the female respondents (in 28 out of 
Table III. Complications after sialendoscopy

\begin{tabular}{|lc|}
\hline Complications & $\begin{array}{c}\text { Number } \\
\text { of patients }\end{array}$ \\
\hline No complications & $63(63 \%)$ \\
\hline Salivary gland inflammation & $4(4 \%)$ \\
\hline Transient salivary gland swelling & $33(33 \%)$ \\
\hline Minor pain and elevated body temperature & $11(11 \%)$ \\
\hline
\end{tabular}

Table IV. Assessment of results of sialendoscopy in 100 consecutive patients

\begin{tabular}{|lc|}
\hline Postoperative results & $\begin{array}{c}\text { Number } \\
\text { of patients }\end{array}$ \\
\hline Relief of symptoms after sialendoscopy & $64(64 \%)$ \\
\hline $\begin{array}{l}\text { Partial relief of symptoms after sialendos- } \\
\text { copy }\end{array}$ & $18(18 \%)$ \\
\hline $\begin{array}{l}\text { No relief of symptoms after sialendoscopy } \\
\text { (persistent symptoms) }\end{array}$ & $16(16 \%)$ \\
\hline $\begin{array}{l}\text { Deterioration of symptoms after sialendos- } \\
\text { copy }\end{array}$ & $2(2 \%)$ \\
\hline Approach subjectively rated as very good & $71(71 \%)$ \\
\hline $\begin{array}{l}\text { Approach subjectively rated as good or } \\
\text { satisfactory }\end{array}$ & $25(25 \%)$ \\
\hline Approach subjectively rated as bad & $4(4 \%)$ \\
\hline
\end{tabular}

$67 ; 41.8 \%)$ as compared to the male respondents (in 7 out of 33; 21.2\%), the correlation between the patients' gender and the incidence of complications was statistically not significant. The study also analysed the correlation between subjective and objective complications, which was statistically insignificant. The group without complications and the group with complications did not significantly differ in the distribution of symptom duration. Similarly, no correlation was found between the number of previously performed procedures and complications after sialendoscopy.

\section{Relief of ailments}

Relief of previous symptoms was reported by 64 patients (64\%), with partial relief found in 18 patients (18\%). In 16 patients (16\%) the intensity of symptoms was the same as at baseline. Only 2 patients (2\%) reported deterioration of symptoms after endoscopy. Neither relief nor persistence of the symptoms correlated with the patients' age, gender, duration of anamnesis or the number of earlier non-endoscopic procedures. The efficacy of concrement removal was at the level of $82 \%$.

\section{General assessment of patient satisfaction with the sialendoscopic procedure}

The next question concerned an issue which was difficult to define, namely the level of patient subjective satisfaction with the sialendoscopy. The approach was rated as very good and good by $71(71 \%)$ and $10(10 \%)$ patients respectively. Fifteen patients (15\%) who developed atypical complications rated the procedure as satisfactory, and only 4 patients (4\%) rated the approach as bad. These were patients with concrements that could not be removed due to their nature or location. The final assessment of the level of satisfaction with sialendoscopy was not correlated with patients' age. Patients with a mean age of 55.7 years rated the approach as very good, while patients with a mean age of 52.3 and 50 years rated the approach as good or satisfactory and bad, respectively. The rating also did not depend on gender. Similarly, the duration of ailments did not have any effect on the evaluation of the approach: the groups divided according to procedure rating did not significantly differ in the distribution of ailment duration. The number of previously performed procedures did not influence the general assessment of the approach either. Conversely, the division of the studied sample into previously treated patients (47 patients) and untreated ones (53 patients) showed that $75 \%$, $21.4 \%$ and $3.6 \%$ of the patients with a history of non-endoscopic treatment for sialolithiasis as well as $68.8 \%, 23.5 \%$ and $7.7 \%$ of patients treated using sialendoscopy for the first time rated this approach as very good, good and bad, respectively. The log linear analysis, carried out for the following variables - number of sialendoscopic procedures, treatment outcome and general rating of the level of satisfaction with the treatment - showed no effect of the variable representing complications on the remaining variables. Despite the complications, 24 patients (50\%) still rated the method as very good, 20 patients $(41.7 \%)$ rated it as satisfactory, and 4 patients $(8.3 \%)$ rated it as bad. At the same time, a statistically significant correlation was found between the treatment outcome and the general assessment of the level of satisfaction with the treatment. Among the patients with total resolution of symptoms, 92.3\% rated the approach as very good, while from among 47 patients with a history of non-endoscop- 
ic procedures this percentage increased to $96.4 \%$. Among the patients with partial and no improvement, $27 \%$ and $9 \%$, respectively, rated the approach as very good.

\section{Discussion}

Sialendoscopy is a safe procedure [4-8]. In our group, 63 patients (63\%) did not report any postoperative complications. Thirty-three patients (33\%) reported swelling of the submandibular or parotid region, which according to the literature on the topic [8] is normal within $48 \mathrm{~h}$ following the procedure. Maresh et al. observed transient swelling of the gland in all studied individuals, and after 2 out of 37 procedures conducted in a group of 18 patients observed purulent sialadenitis, which was managed by antibiotics [9]. In this study, inflammation of the salivary gland was observed as a postoperative complication in 4 patients (4\%), while 11 patients (11\%) reported elevated body temperature and pain.

According to the learning curve of each centre, results of sialendoscopic treatment of salivary gland stenosis and sialolithiasis improve progressively, with failures of this technique, as reported in the literature, ranging from 3.2 to $10.9 \%$ [10]. In this study, in 16 patients (16\%), the intensity of ailments was the same as at baseline, and only 2 patients (2\%) reported deterioration of the symptoms after the endoscopic procedure. The results are only seemingly worse as compared with the literature data, since they concern only the patients with concrements, including almost half of the patients (47\%) after previous failures of the non-endoscopic treatment. In the literature, the efficacy of endoscopic removal of concrements ranges from 61\% (Luers et al.) [11], 67\% (lanovski et al.) [8], 82\% (Nahlieli and Baruchin) [12], and $85.2 \%$ (Kroll et al.) [7] up to 90\% (Lari et al.) [13].

Results of the endoscopic treatment are good and complications are not very severe. This statement is reflected by the general evaluation of the degree of patient satisfaction with sialendoscopy, obtained by means of the questionnaire distributed among the patients with a history of conventional sialolith removal. The results presented in this study indicate that the group of patients with adverse experience could appreciate low invasiveness and only slight discomfort of the endoscopic treatment. From the total of 71 respondents only 4 patients (4\%) rated the approach as bad. These, however, were the patients in whom the attempt to remove con- crements failed due to the nature or location of the sialoliths. Interestingly, in the group of patients with complications, 24 patients (50\%) still rated the approach as very good and 15 patients (31.3\%) rated it as satisfactory.

Patient satisfaction is one of the criteria of implementation and propagation of new therapeutic approaches. While in the literature on the topic there are reports about high efficacy of this therapeutic approach with only a few contraindications, complications and side-effects [14], only two studies have been conducted so far that evaluated the level of patient subjective satisfaction with the approach $[7,8]$. In a group of 46 patients described by Kroll et al. [7], $82.5 \%$ of patients reported an improvement of symptoms during follow-up. To determine patient satisfaction, a self-made questionnaire was applied and evaluated. In a group of 54 patient described by lanovski et al. [8], to measure patient satisfaction the Glasgow Benefit Inventory (GBI) questionnaire was administered. The overall mean $\mathrm{GBI}$ score was +31 , which compares very favourably with other otolaryngology procedures. In our group, from among 100 patients with sialolithiasis, 92.3\% subjectively rated sialendoscopy as a very good or good approach, while from among 47 patients with a history of non-endoscopic procedures this percentage increased to $96.4 \%$. The overall level of satisfaction with the procedure did not depend on such factors as patients' age, gender, duration of symptoms, number of previous procedures, number of sialendoscopic procedures necessary to obtain improvement, or postoperative complications.

\section{Conclusions}

Sialendoscopy is a safe procedure and can be performed in almost any case (apart from definite contraindications) without risking patients' discomfort, pain or unpleasant experience. Based on the patients' rating, the study confirmed that sialendoscopy is a minimally invasive technique.

\section{References}

1. Katz P. Endoscopie des glandes salivaires. Ann Radiol 1991; 34: 110-13.

2. Katz P. New technigues for the treatment of salivary lithiasis: sialoendoscopy and extracorporal lithotripsy: 1773 cases. Ann Otolaryngol Chir Cervicofac 2004; 121: 123-32.

3. Marchal F, Dulgerov P. Sialolithiasis management: the state of the art. Arch Otolaryngol Head Neck Surg 2003; 129: 951-6. 
4. Kopeć T, Szyfter W. Sialendoscopy as a non-invasive treatment method of sialolithiasis and non-inflammatory processes causing salivary gland swelling. Otolaryngol Pol 2010; 64: 370-4.

5. Kopeć T, Szyfter W, Wierzbicka M, et al. Sialendoscopy in treatment of sialolithiasis: our own experience based on group of 95 patients. Otolaryngol Pol 2012; 66 (4 Suppl): 11-4.

6. Kopeć T, Wierzbicka M, Szyfter W. Stensen's duct injuries: the role of sialendoscopy and adjuvant botulinum toxin injection. Videosurgery Miniinv 2013; 8: 112-6.

7. Kroll T, Finkensieper M, Sharma SJ, et al. Short-term outcome and patient satisfaction after sialendoscopy. Eur Arch Otorhinolaryngol 2013; 270: 2939-45.

8. lanovski I, Morton RP, Ahmad Z. Patient-perceived outcome after sialendoscopy using the Glasgow Benefit Inventory. Laryngoscope 2014; 124: 869-74.

9. Maresh A, Kutler DI, Kacker A. Sialoendoscopy in the diagnosis and management of obstructive sialadenitis Laryngoscope 2011; 121: 495-500.

10. Walvekar RR, Carrau RL, Schaitkin B. Sialendoscopy: minimally invasive approach to the salivary ductal system. Operative Tech In Otolaryngology 2009; 20: 131-5.

11. Luers JC, Grosheva M, Reifferscheid V, et al. Sialendoscopy for sialolithiasis: early treatment, better outcome. Head Neck 2012; 34: 499-504.

12. Nahlieli O, Baruchin AM. Long-term experience with endoscopic diagnosis and treatment of salivary gland inflammatory diseases. Laryngoscope 2000; 110: 988-93.

13. Lari N, Chossegros C, Thiery G, et al. Sialendoscopy of the salivary glands. Rev Stomatol Chir Maxillofac 2008; 109: 167-71.

14. Nahlieli O, Schaham R, Bar T, et al. Endoscopic mechanical retrieval of sialoliths. Oral Surg Oral Med Oral Pathol Oral Radiol Endod 2003; 95: 396-402.

Received: 9.01.2014, accepted: 30.04.2014. 